\title{
Risk Factors Associated with Stillbirth in Swine Farms in Vietnam
}

\author{
Nguyen Hoai Nam $^{1 *}$ and Peerapol Sukon ${ }^{2,3}$ \\ ${ }^{I}$ Faculty of Veterinary Medicine, Vietnam National University of Agriculture, Vietnam \\ ${ }^{2}$ Faculty of Veterinary Medicine, Khon Kaen University, Thailand \\ ${ }^{3}$ Research Group for Animal Health Technology, Khon Kaen University, Thailand \\ *Corresponding's Email: hoainam26061982@yahoo.com; (D ORCiD: 0000-0002-2110-0006
}

\begin{abstract}
Stillbirth in pigs has been studied worldwide, but, its situation in Vietnam has never been reported. Therefore, the present study aimed to investigate the effects of herd, parity, gestation length, birth litter size and farrowing duration on stillbirth at sow level in swine farms in Vietnam. Data was collected from 1174 litters of 1174 Landrace $\mathrm{x}$ Yorkshire crossbred sows in 16 farms in the North of Vietnam. Potential risk factors for stillbirth were identified by using logistic regression. The incidence of stillbirth at sow level was $47.9 \%$, and the stillbirth rate was 5.2\%. Multivariate logistic regression showed that parity $1(\mathrm{OR}=1.81,95 \% \mathrm{CI}=1.24-2.63)$ and $>4(\mathrm{OR}=1.87$, $95 \% \mathrm{CI}=1.33-2.64)$, a gestation length $<114$ days $(\mathrm{OR}=1.80,95 \% \mathrm{CI}=1.23-2.65)$, a birth litter size $\geq 9$ piglets $(\mathrm{OR}=1.64,95 \% \mathrm{CI}=1.04-2.61)$ and a farrowing duration $\geq 5$ hours $(\mathrm{OR}=1.48,95 \% \mathrm{CI}=1.05-2.09)$ were risk factors for stillbirth. This study indicated that stillbirth was common in swine farms in Vietnam. Special attention should be paid to sows at parity $1,>4$, sows with a short gestation, sows with a large birth litter size and sows with a long farrowing duration to reduce stillbirth. Since the use of highly prolific sows is increasing, stillbirth continues to be an issue to be dealt with in swine farms in Vietnam.
\end{abstract}

Keywords: Farrowing, Gestation length, Litter size, Parity, Sow, Stillbirth

\section{INTRODUCTION}

In recent decades, pig production has focused on increasing birth litter size (Koketsu et al., 2017). However, large litter size positively correlates with long farrowing duration and increases stillbirth rate (Fahmy and Friend, 1981; Borges et al., 2005; Vanderhaeghe et al., 2010). Stillborn piglets can be classified as non-fresh, prepartum, intrapartum and postpartum in which the third type accounts for $66.8 \%$ (Leenhouwers et al., 2003). Intrapartum stillborn piglets are attributable to various factors including maternal and piglet traits as well as management and pharmacological interventions (Leenhouwers et al., 1999; Cozler et al., 2002; Lucia et al., 2002; Borges et al., 2005; van Dijk et al., 2005; Canario et al., 2006; Mota-Rojas et al., 2006; Vanderhaeghe et al., 2010).

Currently, no studies on factors associated with stillbirth in swine farms in Vietnam are available. Therefore, the present study aimed to evaluate the effect of herd, parity, gestation length, litter size and farrowing duration on stillbirth in pig farms in Vietnam.

\section{MATERIALS AND METHODS}

\section{Ethical approval}

This observational study was performed according to all ethics and animal rights of Vietnam National University of Agriculture, Vietnam.

\section{Animals}

This observational study was conducted from August 2016 to November 2017; included 1174 sows in 16 swine farms from 6 provinces in the North of Vietnam. All farms had a breeding herd of 200-700 sows. During gestation, sows were housed in individual crates sized $57 \mathrm{~cm}$ width x $220 \mathrm{~cm}$ length. Approximately a week before estimated farrowing date, animals were moved to individual farrowing crates sized $180 \mathrm{~cm}$ width $\times 220 \mathrm{~cm}$ length. A 60 x $220 \mathrm{~mm}$ slatted floor in the farrowing crates was assigned for each sow.

During the first 84 days of gestation, sows were daily fed 1.8-2.5 kg of feed containing $13 \%$ of crude protein and a metabolizable energy of $2900 \mathrm{Kcalo} / \mathrm{kg}$ (Hi-Gro 566, Charoen Pokphand, Vietnam). At the last trimester, sows daily 
received 3.0-3.5 kg of feed containing $17 \%$ crude protein and a metabolizable engery of $3100 \mathrm{Kcalo} / \mathrm{kg}$ (Hi-Gro $567 \mathrm{~S}$, Charoen Pokphan, Vietnam). At parturition, no feed was available to sows. Water was provided ad libitum through a bite nipple system.

\section{Data and definition}

Before parturition, parity number was recorded, and classified as parity 1, parity 2-4 and parity $>4$. At farrowing, birth litter size, gestation length, stillbirth and farrowing duration were recorded. Stillborn piglets were defined as those died before being expulsed and had no signs of decay (Vanderhaeghe et al., 2010). The incidence of stillbirth at sow level was the proportion of litters with stillborn piglet(s) to all litters. Stillborn rate was the proportion of all stillborn piglets to total born piglets of all litters. Birth litter size was defined as number of piglets born/litter (number of live born piglets and stillborn piglets). Birth litter size was allocated into 2 categories, i.e. $<9$ and $\geq 9$ piglets/litter. Gestation length was the interval between the date of the first artificial insemination and the date of farrowing, and was divided into 2 categories ( $<114$ and $\geq 114$ days). Farrowing duration was defined as the interval between the first and the last piglet expulsion, and was classified as $<5$ and $\geq 5$ hours. During farrowing, all sows were injected with oxytocin, the number of administrations, the dose, and the time of injection, however, were not recorded.

\section{Statistical analysis}

All statistical analyses were conducted in SPSS program (SPSS Statistics for Windows, Version 22.0, Armonk, NY: IBM Corp). Descriptive statistics for parity, gestation length, birth litter size, farrowing duration and stillbirth were generated from all available data of 1174 sows (Table 1). Due to missing data of 363 sows, full records of 811 sows were included in risk analyses. The incidence of stillbirth at sow level among herds was compared by means of the Chi-square test of association. Potential risk factors for stillbirth were herd (1-16), parity number (parity 1, parity 2-4 and parity > 4 ), gestation length $(<114$ and $\geq 114$ days), birth litter size $(<9$ and $\geq 9$ piglets/litter) and farrowing duration $(<5$ and $\geq$ 5 hours). The binary dependent variable was defined as presence of at least one stillborn piglet or absence of stillborn piglet(s) in a given litter (Vanderhaeghe et al., 2010).

Univariate logistic regression was used to analyze effects of individual potential risk factors on stillbirth. Risk factors conferring a significant value at $\mathrm{P}<0.15$ by Wald's test (2-tailed) were used for calculation of Pearson's correlation and variance inflation factor (VIF) to detect multicollinearity. Only risk factors that had low Pearson's correlation $(\mathrm{r}<0.3)$ and low VIF (VIF < 5) were used to build multivariate logistic regression models. Based on biological plausibility and correlations, 4 risk factors including parity number, birth litter size, gestation length and farrowing duration were enrolled in the multivariate analysis. Multivariate models were built by enrolling the backward stepwise elimination of non-significant factors $(\mathrm{P}>0.1)$. The predictability of the multivariate models was measured by Hosmer-Lemeshow goodness of-fit tests.

Table 1. Descriptive statistics for reproductive parameters of 1174 sows in 16 commercial swine herds in Vietnam

\begin{tabular}{lccc}
\hline Characteristics & Number of sows & Mean \pm SD/Percentage & Range \\
\hline Parity & 1174 & $3.5 \pm 2.2$ & $1-13$ \\
Gestation length (days) & 1020 & $114.8 \pm 1.6$ & $105-126$ \\
Farrowing duration (hour) & 957 & $3.6 \pm 1.8$ & $1.0-9.5$ \\
Birth litter size & 1174 & $12.4 \pm 3.0$ & $3-25$ \\
Incidence of stillbirth at sow level (\%) & 1174 & $47.9(562 / 1174)$ & - \\
Stillbirth rate (\%) & 1174 & $5.2(756 / 14542)$ & - \\
\hline SD: standard deviation & & &
\end{tabular}

\section{RESULTS}

In the Table 1, totally $47.9 \%$ of the litter had at least one stillborn piglet, and 5.2\% (756/14542) of piglets were stillborn. Gestation length, birth litter size and farrowing duration were $114.8 \pm 1.6$ days, $12.4 \pm 3.0$ and $3.6 \pm 1.8$ hours, respectively. The incidence of stillbirth at sow level did not significantly differ among 16 herds $(37.5 \%-60.8 \%, \mathrm{P}=$ 0.35). Table 2 shows the results for univariate analysis of individual factors for stillbirth at sow level. Herd had no effect on the stillbirth. By contrast, parity, birth litter size, gestation length and farrowing duration all associated with stillbirth. Among risk factors for stillbirth, gestation length had a very low association with parity $(\mathrm{r}=-0.099)$ and farrowing duration $(\mathrm{r}=-0.082)$. There was no association among other factors. Besides, VIF for parity, birth litter size, gestation length and farrowing duration were 1.010, 1.004, 1.017 and 1.011, respectively. Therefore, all significant factors derived from univariate analysis were retained for the multivariate analysis. Table 3 shows the final multivariate logistic regression. Sows at parity 1 and parity $>4$ had respective $1.81(\mathrm{P}=0.002)$ and $1.87(\mathrm{P}<0.001)$ times higher odds for stillborn piglets compared with sows at parity $2-4$. A birth litter size $\geq 9$ significantly increased the risk for stillbirth 
compared with a birth litter size $<9(\mathrm{OR}=1.64, \mathrm{P}=0.035)$. Sows with a gestation length $<114$ days had 1.80 times higher odds for stillbirth compared with sows with a gestation length $\geq 114$ days $(\mathrm{P}<0.001)$. Sows with a farrowing duration $\geq 5$ hours had significant higher odds for stillbirth compared with sows with a farrowing duration $<5$ hours (OR $=1.48, \mathrm{P}=0.026)$. The multivariate model conferred 56.7\% "percentage correct". Hosmer Lemeshow test showed that the model had a good fit between the observed and expected incidence of stillbirth at sow level $(\mathrm{P}=0.899)$.

Table 2. Results of univariate logistic regression for association between potential risk factors and stillbirth in 16 Vietnamese swine farms (2016-2017).

\begin{tabular}{|c|c|c|c|}
\hline Characteristics & $\begin{array}{c}\text { Incidence of stillbirth } \\
\text { at sow level }(\%)^{\mathrm{a}}\end{array}$ & $O R^{b}(95 \% C I)^{c}$ & $P$ value \\
\hline Herd & - & - & 0.364 \\
\hline Farrowing duration $<5 \mathrm{hrs}$ & $48.8(308 / 631)$ & Reference & \\
\hline Farrowing duration $\geq 5 \mathrm{hrs}$ & $60.0(108 / 180)$ & $1.57(1.12-2.20)$ & 0.008 \\
\hline Gestation length $\geq 114$ days & $48.4(324 / 669)$ & Reference & \\
\hline Gestation length $<114$ days & $64.8(92 / 142)$ & $1.96(1.35-2.85)$ & $<0.001$ \\
\hline Parity 2-4 & $44.4(202 / 455)$ & Reference & \\
\hline Parity 1 & $59.0(92 / 156)$ & $1.80(1.25-2.60)$ & 0.002 \\
\hline Parity $>4$ & $61.0(122 / 200)$ & $1.96(1.40-2.75)$ & $<0.001$ \\
\hline Birth litter size $<9$ & $43.2(38 / 88)$ & Reference & \\
\hline Birth litter size $\geq 9$ & $52.3(378 / 723)$ & $1.60(1.02-2.51)$ & 0.04 \\
\hline
\end{tabular}

Table 3. Results of multivariate logistic regression for association between potential risk factors and stillbirth in 16 Vietnamese swine farms (2016-2017).

\begin{tabular}{lcc}
\hline Characteristics & OR $\left.^{\mathbf{a}} \mathbf{( 9 5 \%} \mathbf{C I}\right)^{\mathbf{b}}$ & $\mathbf{P}_{\text {value }}$ \\
\hline Farrowing duration $<5$ hrs & Reference & \\
Farrowing duration $\geq 5$ hrs & $1.48(1.05-2.09)$ & 0.026 \\
Gestation length $\geq 114$ days & Reference & \\
Gestation length $<114$ days & $1.80(1.23-2.65)$ & $<0.001$ \\
Parity 2-4 & Reference & \\
Parity 1 & $1.81(1.24-2.63)$ & 0.002 \\
Parity $>4$ & $1.87(1.33-2.64)$ & $<0.001$ \\
Birth litter size $<9$ & Reference & \\
Birth litter size $\geq 9$ & $1.64(1.04-2.61)$ & 0.035 \\
\hline${ }^{\mathrm{a}} \mathrm{OR}=0 \mathrm{c}$
\end{tabular}

${ }^{\mathrm{a} O R}=$ odds ratio; ${ }^{\mathrm{b}} \mathrm{CI}=$ confidence interval

\section{DISCUSSION}

Studies on risk factors for stillbirth in the pig have been carried out in various countries with numerous results (Vanderhaeghe et al., 2013; Koketsu et a., 2017; Rangstrup-Christensen et al., 2017). However, the present study is the first to determine risk factors for stillbirth in swine farms in Vietnam. The incidence of stillbirth at sow level in this study (47.9\%) is higher in comparison with those in Brazil (27.8\% to 33.1\%) (Lucia et al., 2002; Borges et al., 2005), it is, however, similar to that in Belgium (48\%) (Vanderhaeghe et al., 2010) and in Denmark (44\%) (Rangstrup-Christensen et al., 2017). The stillbirth rate in this study (5.2\%), is within the range of reported results (4.1\%-7.5\%) (Lucia et al., 2002; Borges et al., 2005; Vanderhaeghe et al., 2010; Rangstrup-Christensen et al., 2017; Bhattarai et al., 2019a; 2019b).

Unfavorable association between farrowing duration and stillbirth has been previously substantiated (Van Dijk et al., 2005; Canario et al., 2006; Baxter et al., 2009). Borges et al. (2005) reported that sows with a farrowing duration >3 hours had 2.0 times higher odds for stillbirth when compared with sows with a farrowing duration $\leq 3$ hours. By contrast, Lucia et al. (2002) found that a farrowing longer than 4 hours did not increase the risk for stillbirth. In this study, a farrowing lasting 5 hours was considered normal (Bjorkman et al., 2018), and when a farrowing was considered "prolonged" it increased the risk for stillbirth. During the farrowing process, uterine contraction reduces the blood flow to the placenta and may even break fetal umbilical cords resulting in asphyxia in piglets (Mota-Rojas et al., 2006). Therefore, prolonged farrowing predisposes piglets to increased unfavorable condition, and consequently, to higher risk for stillbirth (Alonso-Spilsbury et al., 2005).

A reverse association between gestation length and stillbirth and stillbirth rate in pig has been widely substantiated (Zaleski and Hacker, 1993; Leenhouwers et al., 1999; Sasaki and Koketsu, 2007; Rydhmer et al., 2008). In another study, a non-existent association between gestation length and stillbirth was suggested to be due to a narrow variation of gestation length (Canario et al., 2006). Gestation length of the pig is widely known to be 114 days. In the present study, $17.5 \%$ sows had early parturition ( $<114$ days) (Table 2$)$. At the time close to term, the lung of swine fetus develops in an 
almost exponential rate, and its development is only fully completed by about 114 days of gestation (Olson, 1979; Kirwood, 2015). Therefore, piglets born before 114 days of gestation might have immature lungs that increased their risk for stillbirth (Rydhmer et al., 2008).

In the present study, sows at parity 1 and parity $>4$ had a higher risk for stillbirth in comparison with sows at parity 2-4 (Table 3). The result partly agrees with that reported by Borges et al. (2005). In that study, sows at parity > 5 had 1.6 times higher odds for stillbirth compared with sows at parity 2-5, sows at parity 1, however, had a lower odds for stillbirth in comparison with sows at parity 2-5 (OR=0.7). Lucia et al. (2002) reported that the incidence of stillbirth at parity $\geq 4$ was 2.2 times higher than that in the parity $2-3$. In the present study, the incidence of stillbirth at parity $2,3,4$ was very close together, i.e. $43.5 \%, 44.8 \%$ and $45.5 \%$, respectively. The effect pattern of parity on stillbirth in this study was somewhat similar to that reported by Vanderhaeghe et al. (2010). In that study, incidence of stillbirth in sows at parity 2 was lower than that in sows at parity 1, 3-6 and >6 (9.7\% vs $26.4 \%, 44.7 \%$ and $19.1 \%$, respectively). The association between stillbirth and higher parities has been suggested to be due to long farrowing durations and large litter sizes in older parities (Borges et al., 2005; Almond et al., 2006). However, it is not a perfect explanation to the association between parity and stillbirth in this study since the proportions of sows at parity $1,2-4$ and $>4$ had a farrowing duration $\geq 5$ hours were not significantly different $(21.2 \%, 21.5 \%$ and $24.5 \%)$. Furthermore, the percentage of sows at parity $2-4$ and $>4$ had a litter size $\geq 9$ was very the same $(89.9 \%$ and $90.0 \%)$ and did not differ from that in parity $1(85.9 \%)$. The result of this study may be partly explained by that the proportion of sows at parity $2-4$ had a gestation length < 114 days tended to be lower than that of sows at parity 1 and > $4(14.3 \%$ vs $19.9 \%$ and $23.0 \%$, respectively, data not shown in the table).

The effect of litter size on the stillbirth found in this study was in agreement with many previous results (Zaleski and Hacker, 1993; Leenhouwers et al., 1999; Knol et al., 2002; Lucia et al., 2002; Borges et al., 2005; Vanderhaeghe et al., 2010). This effect may link to the association between birth litter size and farrowing duration and piglet birth weight. Birth litter size positively correlates with farrowing duration (Van Dijk et al., 2005). Such association also existed in the present study since a higher percentage of sows with a birth litter size $\geq 9$ had a farrowing duration $\geq 5$ hours when compared with sows with a birth litter size $<9(23.2 \%$ vs $14.8 \%)$. A long farrowing may predispose piglets to hypoxia which has been showed to increase the stillbirth of piglets (Borges et al., 2005; Van Dijk et al., 2005; Canario et al., 2006). Furthermore, birth litter size negatively correlates with average birth weight of piglets (Mungate, 1999; Bergstrom et al., 2009). In other word, a larger birth litter size has a lower average birth weight (Akdag et al., 2009). Lighter piglets have lower hemoglobin level in comparison with heavier piglets (Zaleski and Hacker, 1993). During the farrowing process, piglets actively moved through the pelvic canal (Taverne and van der Weijden, 2008). Therefore, it may be hypothesized that heavier piglets participate in farrowing process more efficiently so they had a lower risk for stillbirth (Canario et al., 2006).

As an initial study, the present work has some limitations. Firstly, this study did not differentiate prepartum from intrapartum stillbirth. In the present study, the definition of stillbirth may overestimate the intrapartum stillbirth because piglets died shortly before the onset of parturition may be wrongly defined as intrapartum stillbirth. Secondly, infectious stillbirth, implying most cases of prepartum stillbirth (Sprecher et al., 1974; Borges et al., 2005), was not ruled out in this study. However, the failure of differentiation of stillbirth types should not cause any serious problems in this study because prepartum stillbirth was reported to account for only about 5\% of all cases (Leenhouwers et al., 2003). Thirdly, although oxytocin was used in all studied sows during farrowing its doses, administration routes and time of application were not recorded. Intravenous and intravulval routes may cause more intrapartum stillbirth in comparison with intramuscular route (Mota-Rojas et al., 2006). Also, the use of oxytocin with different doses and/or at different birth order results in different stillbirth rates (Mota-Rojas et al., 2007a; 2007b). Therefore, a detailed record of oxytocin use during parturition will help evaluate the effect of oxytocin on the stillbirth in the swine farms in Vietnam where oxytocin is used ubiquitously and abusively.

\section{CONCLUSION}

The present study indicated that stillbirth in pig was common in swine farms in Vietnam. Parity 1 and $>4$, gestation length $<114$ days, birth liter size $\geq 9$ and farrowing duration $\geq 5$ hours all increased stillbirth. It suggested that, to reduce the stillbirth, all sows, especially those with increased risk should be monitored carefully during farrowing.

\section{DECLARATIONS}

\section{Acknowledgements}

The authors would like to thank Do Xuan Tien, Han Thi Lien, Nguyen Anh Tuan, Nguyen Huy Bang, Nguyen Huyen Trang, Nguyen Thi Ngoc Mai, Nguyen Thi Thuy Hong, Tran Thi Duc, Tran Thi Thanh Dung, Le Thi Cuc, Phan Thi Thanh, Tran Thi Yen, Pham Dinh Khai, Tran Quang Lan, Ha Van Manh, Nguyen Phuong Thu, Tran Van Tuan, Vu 
Duy Tung and Do Hai Yen for their assistance in data collection. This research did not receive any specific grant from funding agencies in the public, commercial, or not-for-profit sectors.

\section{Competing interests}

The authors declare that there is no conflict of interests.

\section{Author's contribution}

Authors contributed equally to this work and checked the final edition of the article for publication in the World's Veterinary Journal.

\section{Consent to publish}

Authors give consent for information concerning the article to be published in the World's Veterinary Journal.

\section{REFERENCES}

Akdag F, Arslan S and Demir H (2009). The effect of parity and litter size on birth weight and the effect of birth weight variations on weaning weight and pre-weaning survival in piglet. Journal of Animal and Veterinary Advances, 8: 2133-2138. Available at: http://docsdrive.com/pdfs/medwelljournals/javaa/2009/2133-2138.pdf.

Almond GW, Flowers WL, Batista L and D'Allaire S (2006). Diseases of the reproductive system. In: Straw B.E., Zimmerman J.J., Allaire S., Taylor D.J. (Eds.). Diseases of Swine. 9th ed. Blackwell Publishing. Ames, Iowa 50014, USA. pp. 113-147.

Alonso-Spilsbury M, Mota-Rojas D, Villanueva-Garcia D, Martinez-Burnes J, Orozco H, Ramirez-Necoechea R, Mayagoitia AL and Trujillo ME (2005). Perinatal asphyxia pathophysiology in pig and human: a review. Animal Reproduction Science, 90: 1-30. DOI: https://doi.org/10.1016/j.anireprosci.2005.01.007.

Baxter EM, Jarvis S, Sherwood L, Robson SK, Ormandy E, Farish M, Smurthwaite KM, Roehe R., Lawrence AB and Edwards SA (2009). Indicators of piglet survival in an outdoor farrowing system. Livestock Science, 124: 266-276. DOI: https://doi.org/10.1016/j.livsci.2009.02.008.

Bergstrom JR, Potter ML, Tokach MD, Henry SC, Dritz SS, Nelssen JL, Goodband RD and DeRouchey JM (2009). Effects of piglet birth weight and litter size on the preweaning growth performance of pigs on a commercial farm. Kansas State University Swine Day 2009. Report of Progress No. 1020. Kansas State Univ., Manhattan. p. 1-7. Available at: https://core.ac.uk/download/pdf/5166099.pdf

Bhattarai S, Framstad T and Nielsen JP (2019a). Association between sow and piglet blood hemoglobin concentrations and stillbirth risk. Acta Veterinaria Scandinavica, 61: 61. Available at: https://actavetscand.biomedcentral.com/articles/10.1186/s13028-0190496-7.

Bhattarai S, Framstad T and Nielsen JP (2019b). Iron treatment of pregnant sows in a Danish herd without iron deficiency anemia did not improve sow and piglet hematology or stillbirth rate. Acta Veterinaria Scandinavica, 61: 60. Available at: https://actavetscand.biomedcentral.com/articles/10.1186/s13028-019-0497-6\#citeas.

Bjorkman S, Oliviero C, Kauffold J, Soede NM and Peltoniemi OAT (2018). Prolonged parturition and impaired placenta expulsion increase the risk of postpartum metritis and delay uterine involution in sows. Theriogenology, 106: 87-92. DOI: https://doi.org/10.1016/j.theriogenology.2017.10.003.

Borges VF, Bernardi ML, Bortolozzo FP and Wentz I (2005). Risk factors for stillbirth and foetal mummification in four Brazilian swine herds. Preventative Veterinary Medicine, 70: 165-176. DOI: https://doi.org/10.1016/j.prevetmed.2005.03.003.

Canario L, Cantoni E, Le Bihan E, Caritez JC, Billon Y, Bidanel JP and Foulley JL (2006). Between-breed variability of stillbirth and its relationship with sow and piglet characteristics. Journal of Animal Science, 84: 3185-3196. DOI: https://doi.org/10.2527/jas.2005-775.

Cozler YL, Guyomarc'h C, Pichodo X, Quinio PY and Pellois H (2002). Factors associated with stillborn and mummified piglets in high-prolific sows. Animal Research, 51: 261-268. DOI: https://doi.org/10.1051/animres:2002017.

Fahmy MH and Friend DW (1981). Factors influencing, and repeatability of the duration of farrowing in Yorkshire sows. Canadian Journal of Animal Science, 61: 17-22. DOI: https://doi.org/10.4141/cjas81-003.

Kirwood RN (2015). Induction of parturition in sows. Thai Journal of Veterinary Medicine, 45: 487-491. Available at: https://www.tci-thaijo.org/index.php/tjvm/article/view/43517.

Knol EF, Ducro BJ, Van Arendonk JAM and van der Lende T (2002). Direct, maternal and nurse sow genetic effects on farrowing, pre-weaning and total piglet survival. Livestock Production Science, 73: 153-164. DOI: https://doi.org/10.1016/S03016226(01)00248-2.

Koketsu Y, Tani S and Iida R (2017). Factors for improving reproductive performance of sows and herd productivity in commercial breeding herds. Porcine Health Management, 3:1. DOI: https://doi.org/10.1186/s40813-016-0049-7.

Leenhouwers JI, van der Lende T and Knol EF (1999). Analysis of stillbirth in different lines of pig. Livestock Production Science, 57: 243-253. DOI: https://doi.org/10.1016/S0301-6226(98)00171-7.

Leenhouwers JI, Wissink P, van der Lende T, Paridaans H and Knol EF (2003). Stillbirth in the pig in relation to genetic merit for farrowing survival. Journal of Animal Science, 81: 2419-2424. DOI: https://doi.org/10.2527/2003.81102419x.

Lucia TJr, Correa MN, Deschamps JC, Bianchi I, Donin MA, Machado AC, Meincke W and Matheus JE (2002). Risk factors for stillbirths in two swine farms in the south of Brazil. Preventative Veterinary Medicine, 53: 285-292. DOI: https://doi.org/10.1016/S0167-5877(01)00288-4. 
Mota-Rojas D, Trujillo ME, Martinez J, Rosales AM, Orozco H, Ramirez R, Sumano H and Alonso-Spilsbury M (2006). Comparative routes of oxytocin administration in crated farrowing sows and its effects on fetal and postnatal asphyxia. Animal Reproduction Science, 92(1-2): 123-143. DOI: https://doi.org/10.1016/j.anireprosci.2005.04.012.

Mota-Rojas D, Villanueva-Garcia D, Alonso-Spilsbury M, Becerril-Herrera M, Ramirez-Necoechea R, Gonzalez-Lozano M and Trujillo-Ortega ME (2007a). Effect of different doses of oxytocin at delivery on suffering and survival of newborn pigs. Journal of Medical Science, 7: 170-178. DOI: https://doi.org/10.3923/jms.2007.170.178.

Mota-Rojas D, Villanueva-Garcia D, Velazquez-Armenta EY, Nava-Ocampo AA, Ramirez-Necoechea R, Alonso-Spilsbury M and Trujillo ME (2007b). Influence of time at which oxytocin is administered during labor on uterine activity and perinatal death in pigs. Biological Research, 40(1): 55-63. DOI: http://dx.doi.org/10.4067/S0716-97602007000100006.

Mungate F (1999). Some non-genetic factors affecting commercial pig production in Zimbabwe. South African Journal of Animal Science, 29(3): 164-173. Available at: https://www.sasas.co.za/journals/some-non-genetic-factors-affecting-commercial-pigproduction-in-zimbabwe/.

Olson EBJ (1979). Role of glucocorticoids in lung maturation. Journal of Animal Science, 49(1): 225-238. DOI: https://doi.org/10.2527/jas1979.491225x.

Rangstrup-Christensen L, Krogh MA, Pedersen LJ and Sorensen JT (2017). Sow-level risk factors for stillbirth of piglets in organic sow herds. Animal, 11: 1078-1083. DOI: https://doi.org/10.1017/S1751731116002408.

Rydhmer L, Lundeheim N and Canario L (2008). Genetic correlations between gestation length, piglet survival and early growth. Livestock Science, 115: 287-293. DOI: https://doi.org/10.1016/j.livsci.2007.08.014.

Sasaki Y and Koketsu Y (2007). Variability and repeatability in gestation length related to litter performance in female pigs on commercial farms. Theriogenology, 68: 123-127. DOI: https://doi.org/10.1016/j.theriogenology.2007.04.021.

Sprecher DJ, Leman AD, Dziuk PD, Cropper M and DeDecker M (1974). Causes and control of swine stillbirths. Journal of American Veterinary Medicine Association, 165(8): 698-701.

Taverne MA and van der Weijden GC (2008). Parturition in domestic animals: targets for future research. Reproduction in Domestic Animals, 43 (Suppl. 5): 36-42. DOI : https://doi.org/10.1111/j.1439-0531.2008.01219.x.

Van Dijk, AJ, van Rens, BT, van der Lende T and Taverne MA (2005). Factors affecting duration of the expulsive stage of parturition and piglet birth intervals in sows with uncomplicated, spontaneous farrowings. Theriogenology, 64: 1573-1590. DOI: https://doi.org/10.1016/j.theriogenology.2005.03.017.

Vanderhaeghe C, Dewulf J, de Kruif A and Maes D (2013). Non-infectious factors associated with stillbirth in pigs: a review. Animal Reproduction Science, 139: 76-88. DOI: https://doi.org/10.1016/j.anireprosci.2013.03.007.

Vanderhaeghe C, Dewulf J, De Vliegher S, Papadopoulos GA, de Kruif A and Maes D (2010). Longitudinal field study to assess sow level risk factors associated with stillborn piglets. Animal Reproduction Science, 120: 78-83. DOI: https://doi.org/10.1016/j.anireprosci.2010.02.010.

Zaleski, HM and Hacker RR (1993). Variables related to the progress of parturition and probability of stillbirth in swine. Canadian Veterinary Journal, 34: 109-113. Available at: https://www.ncbi.nlm.nih.gov/pmc/articles/PMC1686375/. 